\title{
一个相对论性氧原子核在核乳胶中四 分裂事例的遍举测量
}

郑蒲英 孙淑荣 唐孝威

(中国科学院高能物理研究所, 北京)

文献[1]报道了相对论性氧原子核二分裂和三分裂事例的观测。最近我们观察到相对论 性氧原子核在核乳胶中碰撞,碎裂为四个氦原子核的事例. 本文报道事例的测量结果.

能量为 $200 \mathrm{GeV} /$ 核子的相对论性氧原子核是欧洲核子中心 SPS 加速器产生的. 氧原 子核平行于乳胶面, 入射到 $10 \mathrm{~cm} \times 10 \mathrm{~cm} \times 2 \mathrm{~cm}$ 的乳胶叠中. 所用核乳胶为 型. 每层乳胶膜厚度为 $600 \mu \mathrm{m}$. 照射后经 EMU-01 合作组进行显影处理之后, 提供我们分 析 ${ }^{[2]}$.

事例照片见图 1. 放大倍数为 1400 倍. 事例的素描国见图 2(其中代表氦原子核的实粗 线是在一个聚焦平面上, 虚粗线代表另一个聚焦平面上的氦原子核). 人射氧原子核用 $\mathrm{O}$ 表 示, 在作用点 $\mathrm{A}$ 发生碰撞. 碰撞的末态有六个最小电离粒子和四个各为四倍最小电离的碎片 $1,2,3,4$, 而没有反冲核径迹. 四个核碎片与六个最小电离粒子都穿出乳胶片.

在作用点 $A$ 前径迹的 $\delta$ 电子密度等于 $(7.17 \pm 0.62) / 100 \mu \mathrm{m}$, 在作用点 $\mathrm{A}$ 后四个核碎片径 迹的总的 $\delta$ 电子密度等于 $(1.88 \pm 0.24) / 100 \mu \mathrm{m}$. 因此确认在作用点 $\mathrm{A}$ 处氧原子核碎裂为四 个氮原子核。对四个核碎片 $1,2,3,4$ 各在径迹上的 160 个点测定颗粒密度, 在测量误差之 内,均为最小电离值的四倍. 因而证实它们都是 $\alpha$ 粒子. 四个核碎片以很小的发射角沿氧原 子核原来方向飞出. 其中三个核碎片 1,2,4共面, 核碎片 3 靠近此平面而不共面. 四个核碎 片飞行了 $3.04 \mathrm{~mm}$ 之后, 有可察觉的四径迹分开的表现 (见图 1c). 至 $4.55 \mathrm{~mm}$ 处, 四径迹

表 1

\begin{tabular}{c|c|c}
\hline 于 & 电离值 & 赖粒 $/ 100 \mu \mathrm{m}^{*}$ \\
\hline 1 & $75.73 \pm 5.43$ & $(0.22 \pm 0.02) \cdot 10^{-3}$ \\
2 & $75.60 \pm 5.50$ & $(0.11 \pm 0.02) \cdot 10^{-3}$ \\
3 & $76.47 \pm 5.89$ & $(0.25 \pm 0.02) \cdot 10^{-3}$ \\
4 & $75.56 \pm 6.21$ & $(0.19 \pm 0.02) \cdot 10^{-3}$ \\
5 & $25.82 \pm 5.25$ & $0.101 \pm 0.012$ \\
6 & $25.03 \pm 3.71$ & $0.337 \pm 0.012$ \\
7 & $24.22 \pm 5.11$ & $0.295 \pm 0.012$ \\
8 & $24.36 \pm 5.49$ & $0.464 \pm 0.012$ \\
9 & $21.13 \pm 3.70$ & $0.205 \pm 0.012$ \\
10 & $23.64 \pm 4.64$ & $0.145 \pm 0.012$ \\
\hline
\end{tabular}

*平均最小电禹值 $l_{\mathrm{mia}}=(23.78 \pm 4.51) / 100 \mu \mathrm{m}$.

本文 1987 年10月6日收到. 

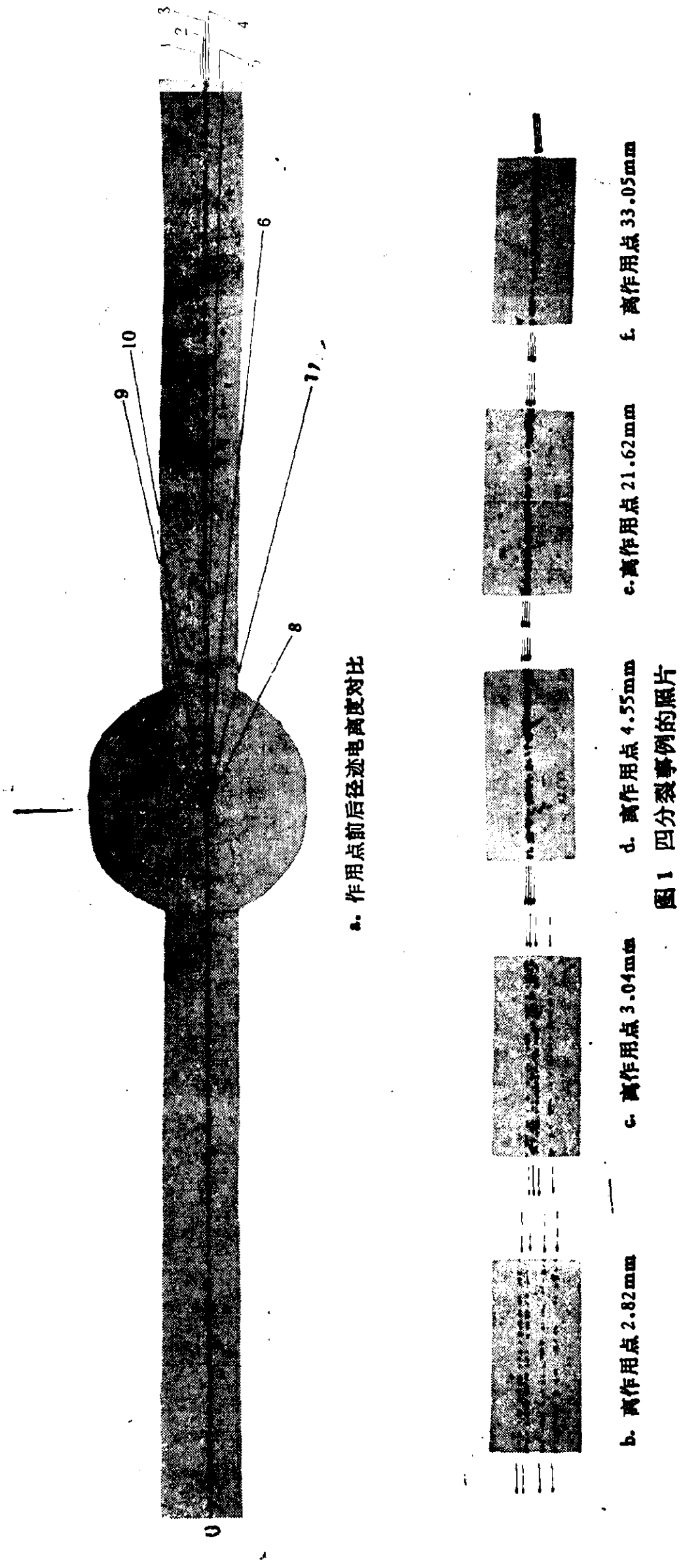


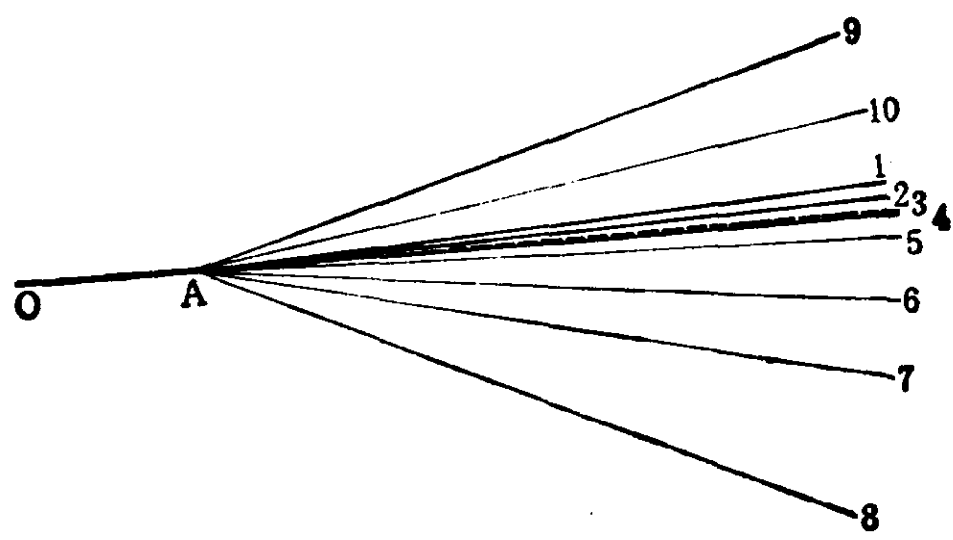

图 2 四分裂事例的示意图

$1 ， 2 ， 3 ， 4$ 柆子的发制角策故大了

较明显地分开. 至 $21.62 \mathrm{~mm}$ 以后, 清晰分开.

表 1 是末态 10 个粒子颗粒密度和发射角的测量结果. 对末态中六个最小电离柆子, 根据 颗粒密度的测量, 并考虑到电荷守恒和核子数守恒, 判断它们是三个 $\boldsymbol{x}^{+}$和三个 $\boldsymbol{x}^{-}$.

这个反应可以解释为:

$$
\mathrm{O}+\mathrm{Z} \longrightarrow \mathrm{Z}+4 \alpha+6 \pi^{ \pm},
$$

即相对论性篻原子核在乳胶中与靶核 $\mathrm{Z}$ 碰撞, 碎裂为四个氦原子核,同时产生 $\pi$ 介子的四分裂 事例. 未态 $Z$ 是乳胶的反冲靶核，因为能量太低而未产生可观测的径迹.

本事例是在扫描观测到的约 300 个作用星中出现的, 即出现的几率为总的作用星 数的 $3.10^{-3}$. 关于这个事例的详细描述及物理机制的讨论将在近期发表.

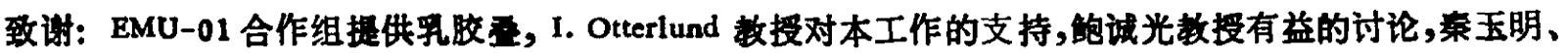
刘福虎、张东海和高不琳诸位同志的初助,在此一并表示感谢.

\section{考文胡}

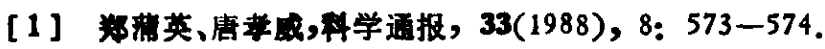

[2] BMU01-Collaboration Cosmic and Subatomic, Physice Report LUIP 8704, Lund, 1987. 